\title{
Current structure in the Rhine region of freshwater influence
}

\author{
by A. J. Souza ${ }^{1}$, J. H. Simpson ${ }^{1}$ and F. Schirmer ${ }^{2}$
}

\begin{abstract}
Observation with HF radar, ADCPs and conventional current meters in the Rhine ROFI system in the North Sea indicate that the dominant currents are due to tidal flow, with important contributions from winds and density-driven circulation. The tidal currents are dominated by the semidiurnal components, principally the M2, with tidal ellipses parallel to the coast and a semimajor axis of the order of $1 \mathrm{~m} \mathrm{~s}^{-1}$ at the surface. The wind-driven flow varies between 1 and $3 \%$ of the wind speed and the rotation varies with depth in qualitative agreement with Ekman theory. After removal of the tidal and wind-driven component the residual fow within this region is generally parallel to the coast (northeastward) with average surface speeds of about $10 \mathrm{~cm} \mathrm{~s}^{-1}$. A convergence zone in the surface flow was observed at the outer edge of the coastal zone. The vertical distribution of residual velocity closely follows the Heaps (1972) profile for density-driven flow, with slight deviations probably due to the tidal rectification $\left(\sim 2 \mathrm{~cm} \mathrm{~s}^{-1}\right)$.
\end{abstract}

\section{Introduction}

The Rhine discharge into the North Sea is responsible for maintaining an extensive region of freshwater influence (ROFI), within which the structure of the flow and density structure is markedly different from that of the adjacent North Sea. Under the influence of the earth's rotation the buoyancy input is deflected to the right and flows to the north along the Dutch coast as it mixes with the ambient water.

In previous papers (e.g., Simpson et al., 1993; Simpson and Souza, 1995; Souza and James, 1996) we have described the basic mixing-stratifying processes operating in this ROFI system and the effect of stratification on the tidal currents (Visser et al., 1994; Souza and Simpson, 1996). In this paper we report in more detail on the nature of the flow field, elucidate the importance of tidal, density and wind-driven circulation and highlight the effect that stratification has on the response to different forms of forcing.

\section{Observations}

The observations were made as part of a European cooperative effort under the MAST PROFILE project. The data sets used here were derived from two observational cam-

1. School of Ocean Sciences, University of Wales Bangor, Menai Bridge I I 59 5F, United Kingdiom.

2. University of Hamburg, Institut fur Meereskunde, Troplowitzstrasse 7, 22529 Hamburg, Germany. 


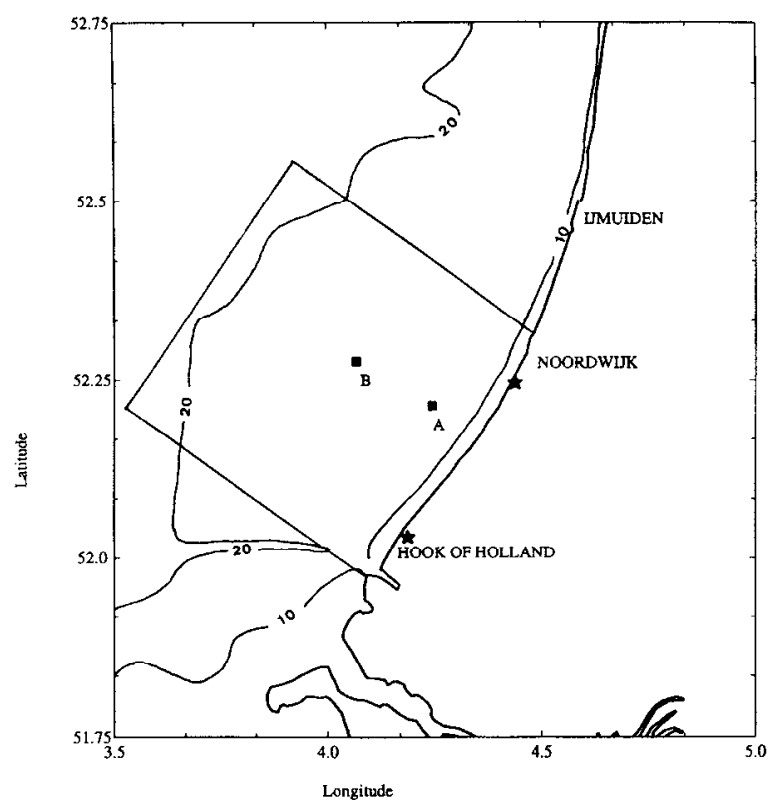

Figure 1. Study area with bathymetry in meters. HF CODAR ground stations, for 1990, are shown as stars and the radar coverage is inside the square; the black squares represent the mooring positions.

paigns, one in September-October 1990 and the other in September 1992; the full description of each data set is given in Simpson et al. (1993) and Simpson and Souza (1995) respectively. In this study we concentrate on the currents recorded by HF radar (CODAR) during October 1990 and by bottom mounted ADCP instruments in 1992. Instrument positions and HF radar coverage are shown in Figure 1.

From 7 to 23 October 1990, surface currents were measured using the CODAR system with ground stations near Hook of Holland and Noordwijk (Fig. 1). This system works on the principle of Doppler shifting of radar echoes from waves (Barrick et al., 1977). The CODAR system has a range of about $60 \mathrm{~km}$ and a spatial resolution of about $3 \mathrm{~km}$. The original data set represented a grid of 17 by 17 grid points over the $51 \times 51 \mathrm{~km}$ area shown in Figure 1, with a two-dimensional vector field integrated over 18 minutes and $28 \mathrm{~km}^{2}$ and recorded every 30 minutes (Visser et al., 1994).

From 2 to 17 September 1992, observations of water column stability and flow were carried out in the Rhine ROFI using a five mooring array. The array formed a square of $13 \mathrm{~km}$ by $13 \mathrm{~km}$ and had a central mooring at about $16 \mathrm{~km}$ offshore from Noordwijk from which moorings A and B from Figure 1 formed the southern side of the square (Fig. 1). Each mooring was equipped with Proudman Oceanographic Lab (POL) Acoustic Doppler Current Profilers (acoustic frequency $1 \mathrm{MHz}$ ), as well as four current meters at depths of approximately $1,10,13$ and 16 meters with the capability of measuring temperature and conductivity. 


\section{Analysis}

We start our analysis by extracting the barotropic tidal currents which generally dominate the flow of kinetic energy. The tidal currents were calculated using harmonic analysis for the main six tidal components $\left(\mathrm{M}_{2}, \mathrm{~S}_{2}, \mathrm{~N}_{2}, \mathrm{O}_{1}, \mathrm{~K}_{1}\right.$ and $\left.\mathrm{M}_{4}\right)$ as explained in Godin (1972). The $u$ and $v$ components for each constituent are combined to form the clockwise and anticlockwise rotary components:

$$
\begin{aligned}
Q_{c} & =\frac{1}{2}\left[u^{2}+v^{2}-2 u v \sin \left(\theta_{v}-\theta_{u}\right)\right]^{1 / 2} \\
Q_{a c} & =\frac{1}{2}\left[u^{2}+v^{2}+2 u v \sin \left(\theta_{v}-\theta_{u}\right)\right]^{1 / 2} \\
\theta_{c} & =\tan ^{-1}\left[\frac{u \sin \theta_{u}+v \cos \theta_{v}}{u \cos \theta_{u}-v \sin \theta_{v}}\right] \\
\theta_{a c} & =\tan ^{-1}\left[\frac{-u \sin \theta_{u}+v \cos \theta_{v}}{u \cos \theta_{u}+v \sin \theta_{v}}\right]
\end{aligned}
$$

where $u, v, \theta_{u}, \theta_{v}$ are the amplitudes and phases for the east-west and north-south components of velocity respectively and $Q_{c}, Q_{a c}, \theta_{c}, \theta_{a c}$ are the amplitudes and phases of the clockwise and anticlockwise rotary components respectively. The characteristics of the tidal ellipses are then determined as:

$$
\begin{aligned}
M & =Q_{a c}+Q_{c} \\
m & =Q_{a c}-Q_{c} \\
\epsilon & =\frac{m}{M} \\
\Theta & =-\frac{1}{2}\left(\theta_{a c}-\theta_{c}\right) \\
\Phi & =\frac{1}{2}\left(\theta_{a c}+\theta_{c}\right) .
\end{aligned}
$$

$M$ and $m$ are the semimajor and semiminor axes respectively, while $\Theta$ and $\Phi$ are the phase and orientation of the semimajor axis. The quantity $\epsilon$ is the ellipticity, its value ranges between 1 (anticlockwise rotation) and -1 (clockwise rotation), with rectilinear currents when $\epsilon=0$.

Although the CODAR has a more or less regular coverage over space and time, some data might be lost at times due to the sea state. This has been taken into account in the tidal analysis in which we have only chosen points where the time series are longer than 8 days and 300 records. The nontidal currents were calculated simply by subtracting the tidal constituents of the currents from the measured velocities and then, to eliminate any effect 
from remaining tidal components, the velocities were filtered using a 19 hours Doodson filter (Pugh, 1987).

In order to estimate the wind-forced current at each level in the water column we follow Prandle and Matthews (1990) and express the nontidal velocities as a scaled and rotated function of the wind velocity together with a steady nonwind-driven component, i.e.,

$$
U_{n t}(t)-U_{0}=a W(t)
$$

where $U_{n t}=u_{n t}+i v_{n t}$ is the total nontidal velocity, $U_{0}=u_{0}+i v_{0}$ is the steady nonwind-forced residual and $a=|a| e^{-i \theta}$ is a complex coefficient with scaling factor $A=$ $|a|$ and veering angle $\theta$ of the current relative to the wind and $W=W_{x}+i W_{y}$ is the wind velocity. Eq. (3) can be rewritten as

$$
\begin{aligned}
& u_{t}=u_{0}+a_{11} W_{x}+a_{12} W_{y} \\
& v_{t}=v_{0}+a_{21} W_{x}+a_{22} W_{y}
\end{aligned}
$$

where $a_{11}=a \cos \theta=a_{22}$ and $a_{21}=a \sin \theta=-a_{12}$.

Values of nonwind-driven residuals and the $a$-coefficients were obtained simultaneously by a complex least-squares regression of wind and current velocities after both had been filtered in the same way for consistency.

\section{Tidal currents}

a. Spatial mapping of ellipse properties. A summary picture of the $\mathrm{M}_{2}$ and $\mathrm{S}_{2}$ horizontal distribution of surface tidal currents for the 1990 experiment, based on HF radar CODAR data is shown in Figure 2. The $\mathrm{M}_{2}$ tidal ellipses (Fig. 2a) are oriented parallel to the coast, with increasing clockwise ellipticity $(\epsilon \sim-0.3)$ near the coast. At about $20 \mathrm{~km}$ from the coast the ellipses become degenerate and farther away they show a weak anticlockwise rotation $(\epsilon \sim 0.08)$, while the semimajor axis is more or less constant at about $0.8 \mathrm{~m} \mathrm{~s}^{-1}$.

The $S_{2}$ ellipses are also more or less oriented parallel to the coast with a semimajor axis of the order of $0.25 \mathrm{~m} \mathrm{~s}^{-1}$, the ellipticity behaves very similarly to that of the $\mathrm{M}_{2}$ constituent, with strong negative ellipticity near the coast and becoming more positive with distance from the coast, but the region where the ellipses rotate clockwise is limited to about $15 \mathrm{~km}$ offshore. A striking difference from the $\mathbf{M}_{2}$ constituent is that the orientation of the tidal ellipses veers to the east as the coast is approached.

b. Vertical distribution. The vertical distribution of tidal characteristics for the 1992 experiment, from the ADCPs at mooring A, is shown in Figures 3 and 4. The behavior of the $\mathrm{M}_{2}$ constituent for mooring A shows that: the semimajor axis has a general tendency to increase with height; there is a corresponding strong decrease in ellipticity for mooring A (Fig. 3b), with the surface ellipticity value of -0.04 and near the bottom value of 0.2 ; this means that the ellipses have changed from strongly anticlockwise near the bottom to slightly clockwise near the surface, with degenerate ellipses at about $12 \mathrm{~m}$ height. Another 

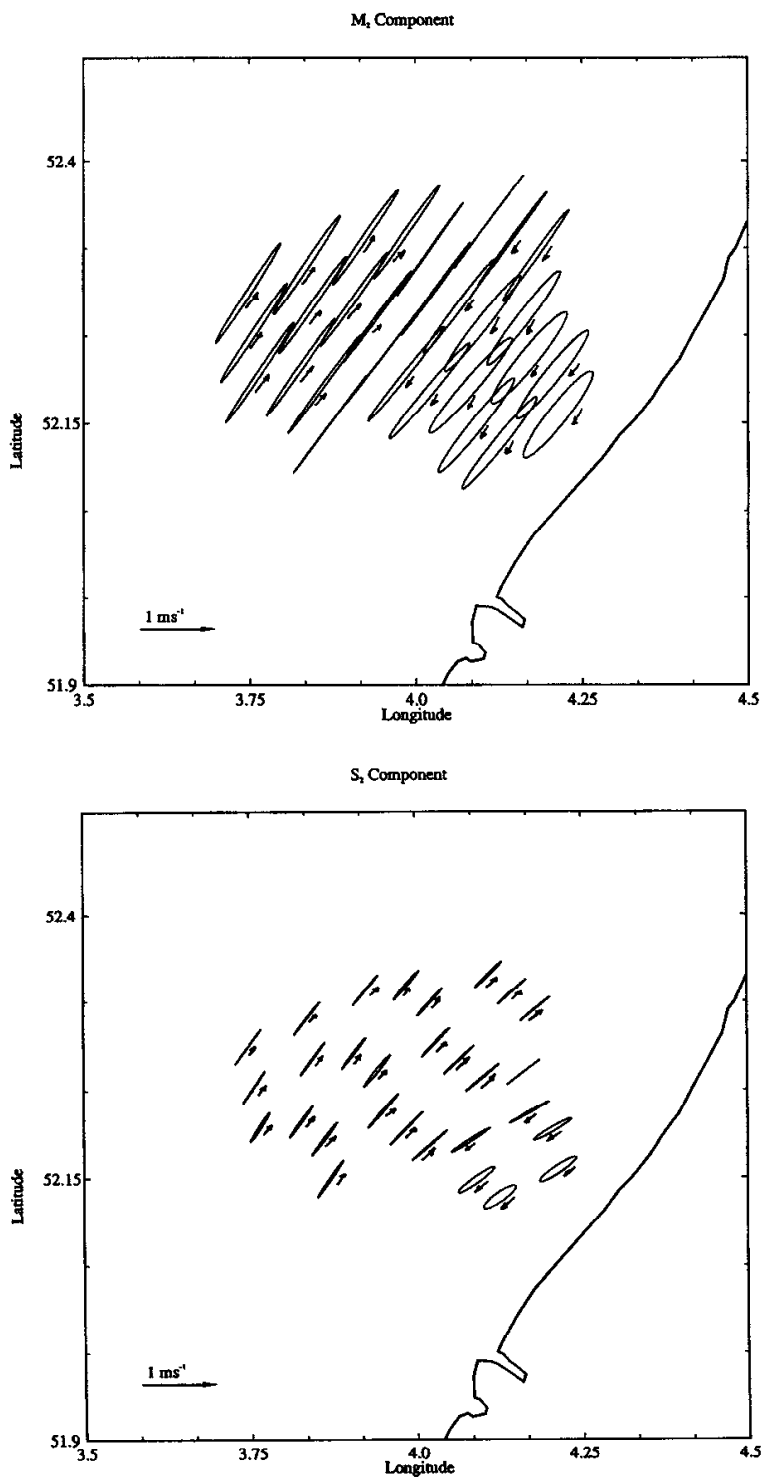

Figure 2. Surface distribution of tidal ellipses from CODAR observations, between 7 and 18 October 1990 (Julian days 280 to 291), (a) $\mathrm{M}_{2}$, (b) $\mathrm{S}_{2}$.

characteristic is that the semimajor axis orientation in mooring A changes approximately $5^{\circ}$ between bottom and surface. The behavior for $S_{2}$ is similar (Fig. 4). The consistent different behavior of the tidal ellipses, particularly the change in ellipticity and orientation, observed in both the CODAR data and in mooring $A$ are due to the effect that stratification has on the 


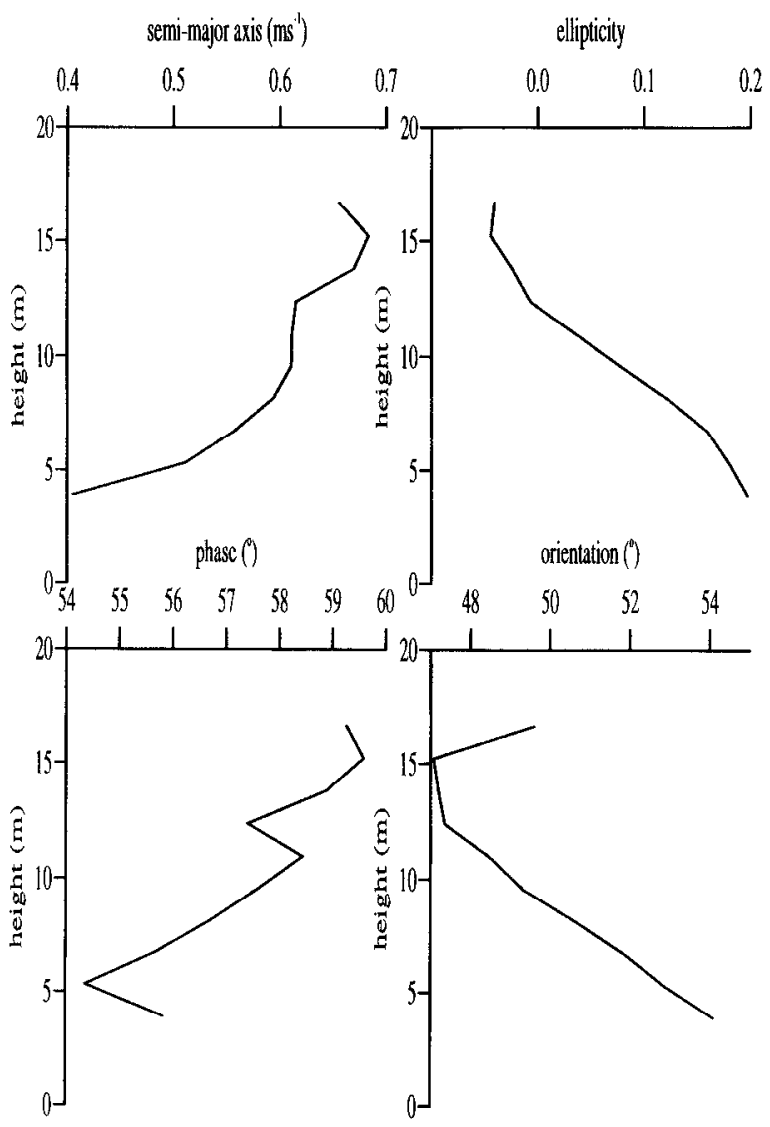

Figure 3. $\mathrm{M}_{2}$ tidal ellipses profiles, from bottom-mounted ADCPs at mooring A, from 2 to 17 September 1992 (Julian days 248 to 261): (a) semimajor axis, (b) ellipticity, (c) phase and (d) orientation.

tidal currents in decoupling the clockwise boundary layer, as explained by Visser $e t$ al. (1994) and Souza and Simpson (1996).

\section{Wind-driven flow}

a. Surface currents. The surface current, for 1990, gathered by the CODAR, show a transfer factor $A=3 \%$ near the coast to about $20 \mathrm{~km}$ offshore, where A decrease to $2 \%$ (Fig. 5a). The rotation angle (Fig. 5b) lies between $15^{\circ}$ and $45^{\circ}$ clockwise, with the maximum values in a "tongue" located in the center-south of the CODAR area.

The percentage of the explained variance of the nontidal currents $\left(R^{2}\right)$ ranges between $55 \%$ in the stratified zone and $80 \%$ in the mixed area, with the isolines bunching near the haline frontal area (Fig. 6). 


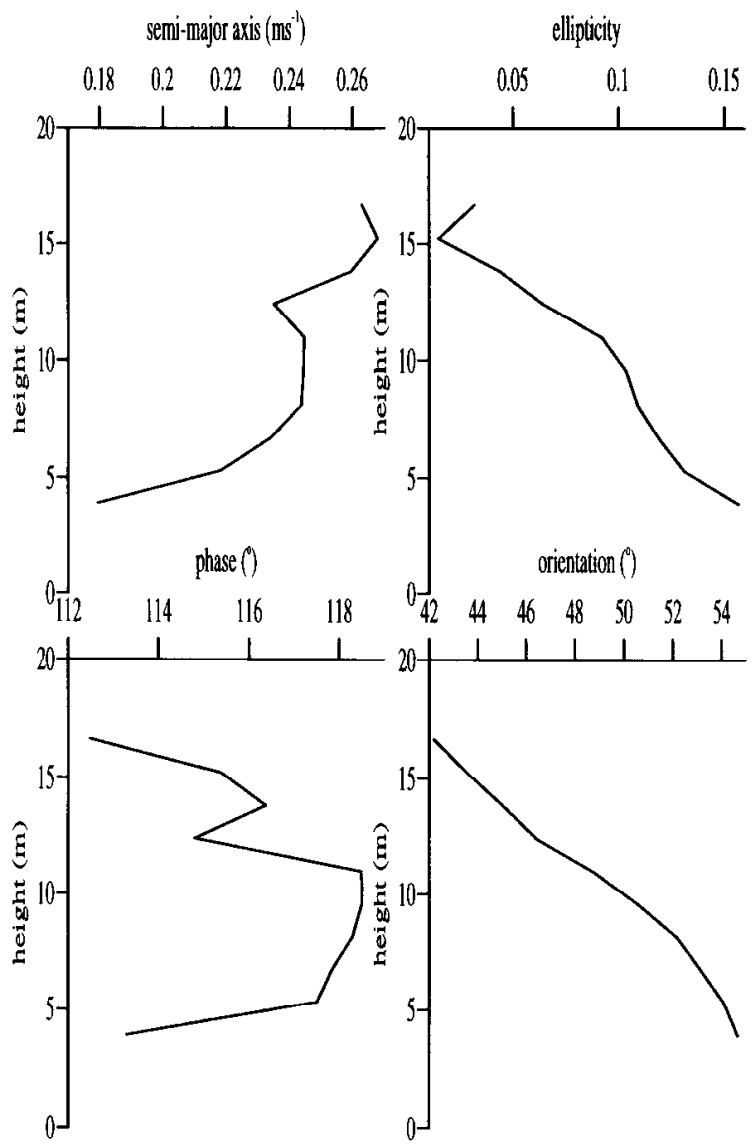

Figure 4. $S_{2}$ tidal ellipses profiles, from bottom-mounted ADCPs at mooring A, from 2 to 17 Septemher 1992 (Iulian days 248 to 261): (a) semimajor axis, (b) ellipticity, (c) phase and (d) orientation.

b. Vertical structure. For the bottom-mounted ADCP data collected in 1992 the profile of A (Fig. 7a), for mooring $\mathrm{A}$ in the stratified area, show a decrease from $1.2 \%$ near the surface to $0.45 \%$ near the bottom with a relative minimum at mid water $(12 \mathrm{~m})$. The veering angle for mooring A exhibits (Fig. 7b) changes between $70^{\circ}$, at the top bin $4 \mathrm{~m}$ from the surface, to $140^{\circ}$, in the bottom bin.

The vertical distribution of $\mathrm{R}^{2}$ shows an S-shaped pattern with two maxima and two minima. The maxima are located near the surface $\left(\mathrm{R}^{2} \sim 30 \%\right)$ and at about $12 \mathrm{~m}$ deep $\left(\mathrm{R}^{2} \sim 35 \%\right.$ ), while the mimima are at about $6 \mathrm{~m}$ deep and near the bottom with an $\mathrm{R}^{2}$ of approximately $15 \%$. It is interesting to observe that both the transfer factor and the explained variance have a minimum at midwater, in a region close to where the pycnocline is observed. 

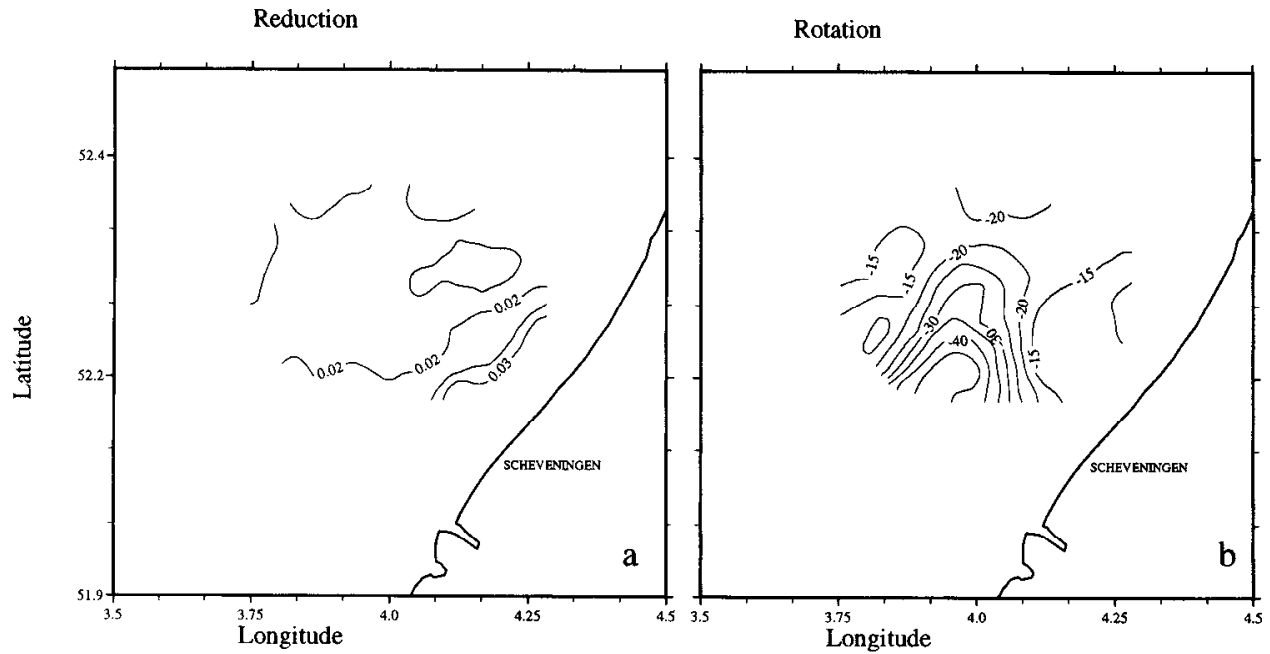

Figure 5. Wind analysis for surface currents mapped by CODAR, from 7 to 23 October 1990: (a) transfer factor; (b) rotation.

\section{Residual flow}

a. Horizontal distribution of the residual currents. As we have discussed in the previous section, the wind accounts for a considerable percentage of the variance of the nontidal flow, especially at the surface. Figure 9a shows the total nontidal residual currents in which we can observe a more or less coherent structure in the entire CODAR domain. The

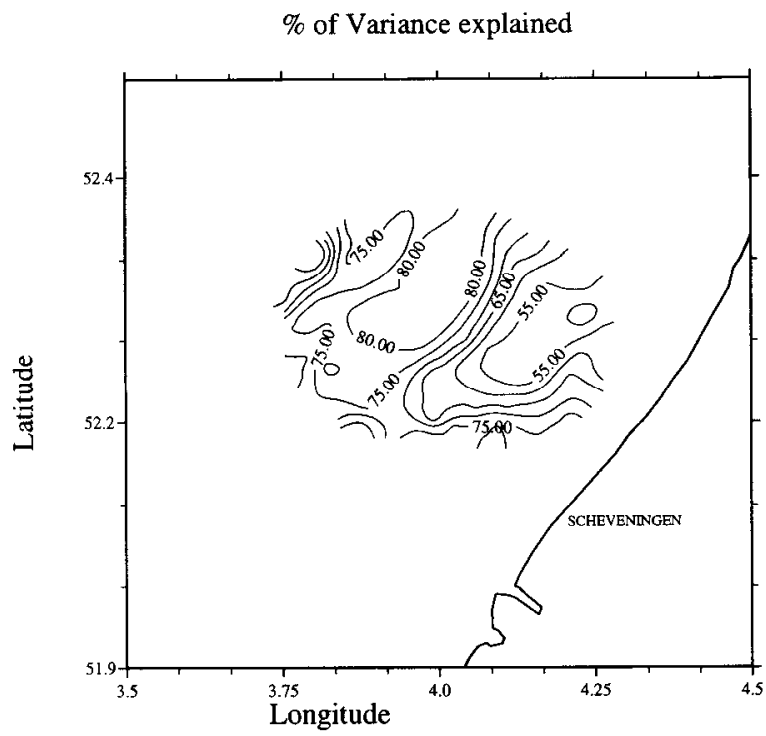

Figure 6. Percentage of variance, of the nontidal currents, explained from the wind analysis. 


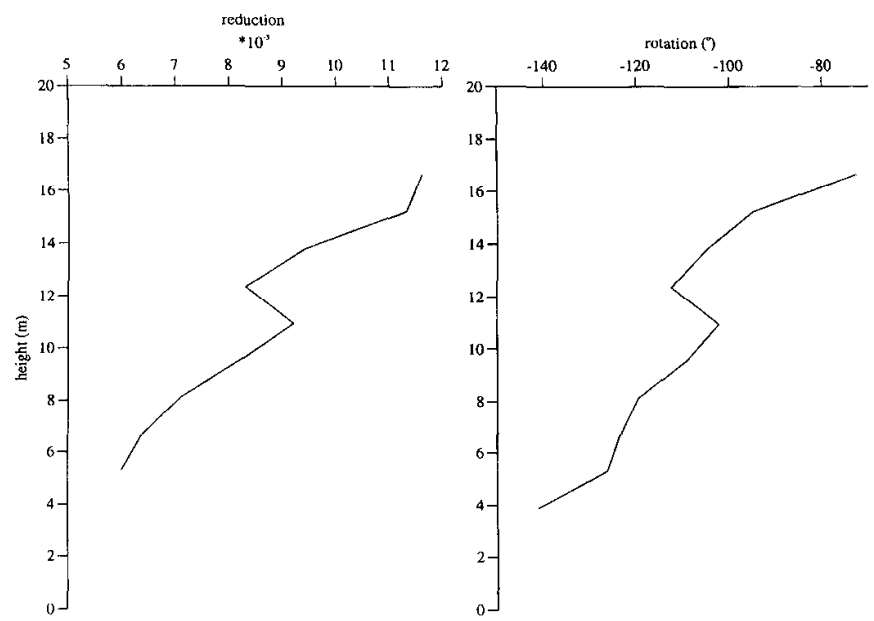

Figure 7. Vertical profile of the wind transfer function from mooring A, from 2 to 17 September 1992: (a) transfer factor; (b) rotation.

currents near the coast appeared to be 2 or 3 times greater than the currents offshore and in a coast-parallel direction, except near to the coast and at the northern boundary of the domain. In the mixed region, the currents are much smaller and gencrally to the north. Once we have removed the wind forcing (Fig. 9b), the currents in the stratified region become more coast-parallel to the northeast, while in the mixed region, the residual flow is generally weak and variable in direction.

If we separate the flow into its cross- and along-shore components, for the 1990 CODAR observations (Fig. 10), we clearly observe both the coastal jet and the convergence zone.

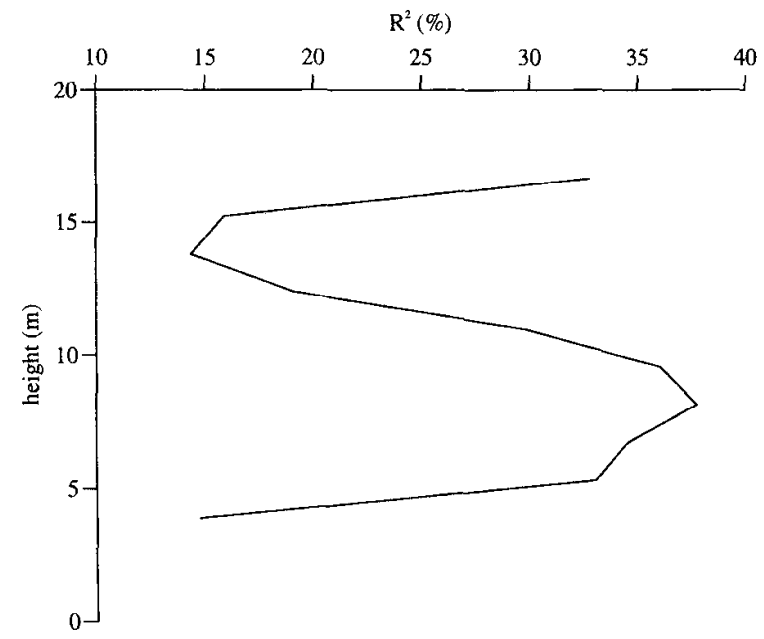

Figure 8. Vertical distribution of the explained variance from the wind analysis of nontidal currents at mooring A, from 2 to 17 September 1992. 

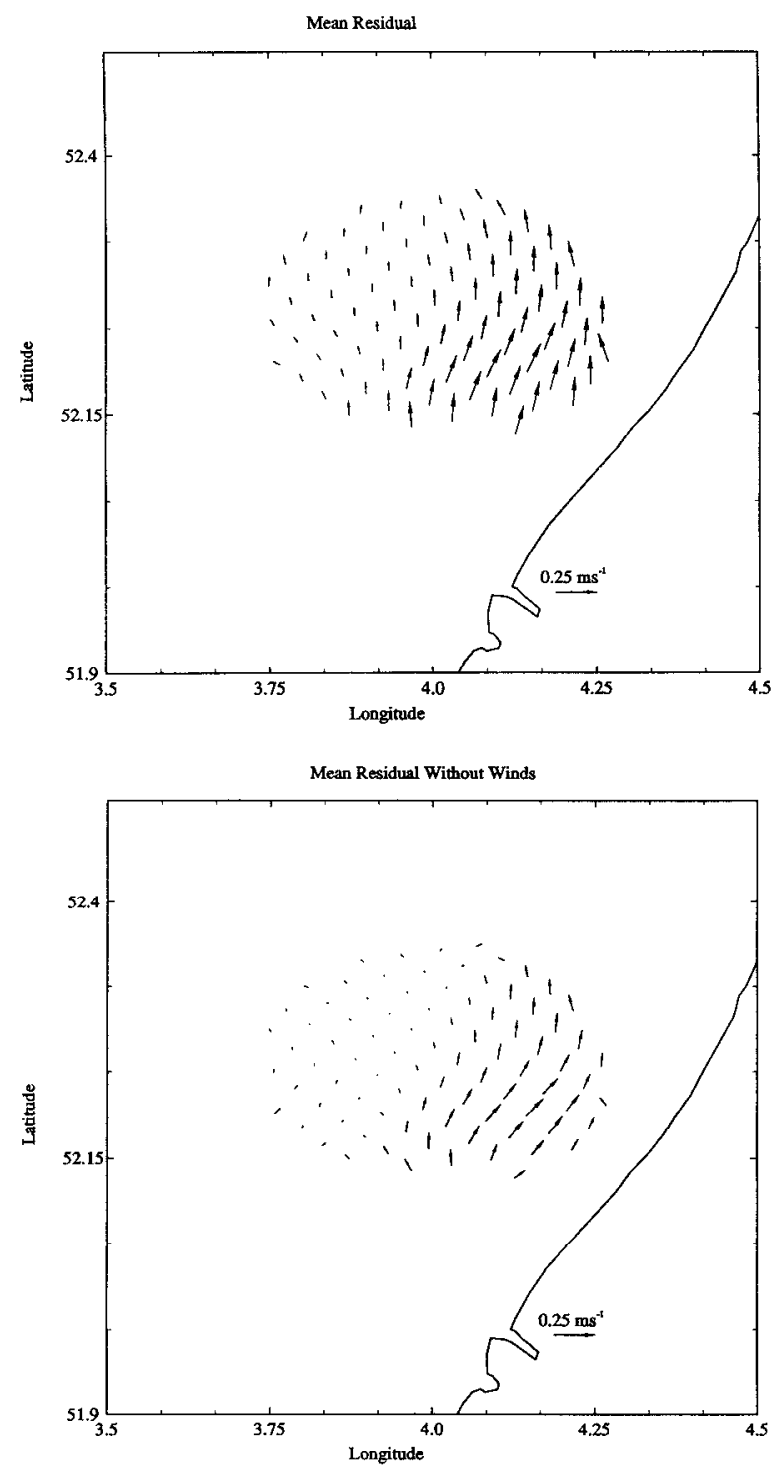

Figure 9. Surface velocity vectors mapped by IfM CODAR from 7 to 23 October 1990: (a) total long term residual; (b) after removing the wind-driven flow.

The cross-shore component of velocity (Fig. 10a), suggests a convergence zone at about $24 \mathrm{~km}$ offshore. The velocities range between $5 \mathrm{~cm} \mathrm{~s}^{-1}$ offshore near the coast, to $2 \mathrm{~cm} \mathrm{~s}^{-1}$ coastward in the open sea. This convergence should be related to the ROFI frontal region. The coastal jet, clearly apparent in Figure 10b, is located between 10 and $20 \mathrm{~km}$ offshore and has a magnitude grater $14 \mathrm{~cm} \mathrm{~s}^{-1}$. Beyond the jet, there is a region of strong shear, with changes in velocity of about $8 \mathrm{~cm} \mathrm{~s}^{-1}$ in $10 \mathrm{~km}$. We should note that the boundary of the jet 

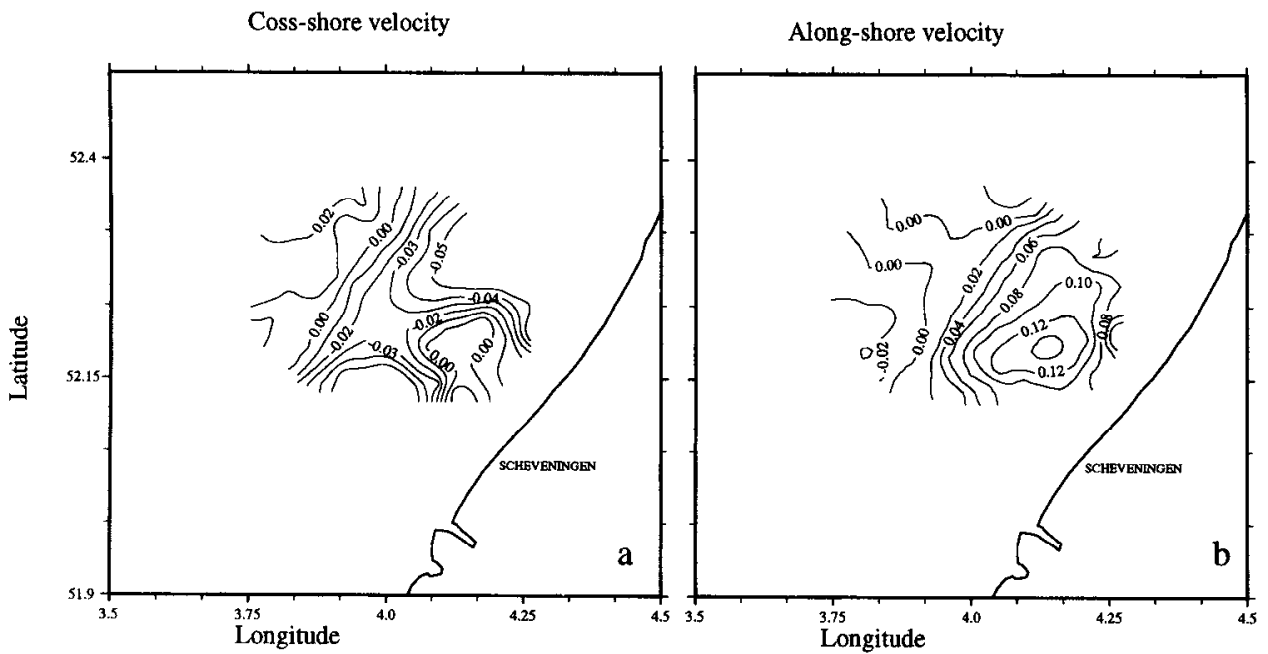

Figure 10. Surface velocity components $\left(\mathrm{m} \mathrm{s}^{-1}\right)$ after removing the wind driven component, between 7 to 23 October 1990: (a) Offshore; (b) alongshore.

coincides with the convergence zone at a distance of the order of $20 \mathrm{~km}$ offshore, which is the approximate position of the Rhine ROFI frontal region during 1990 campaign.

$b$. Vertical structure of the residual current. Estimates of the long-term residual current profile have been obtained from mooring data from the 1992 campaigns. If the main driving forces of the residual currents are the density gradients, the velocities should be comparable to those proposed by the theoretical model of Heaps (1972). The residual flow vectors observed by bottom-mounted ADCPs are compared with Heaps (1972) in Figure 11. The Heaps profile is calculated using a depth of $20 \mathrm{~m}$, a density gradient $(1 / \boldsymbol{\rho})(\partial \boldsymbol{\rho} / \partial x)=$ $2 \times 10^{7} \mathrm{~m}^{1}$ and a vertical exchange coefficient $N_{z}=2.5 \times 10^{3} \mathrm{~m}^{2} \mathrm{~s}{ }^{1}$.

The data for mooring A (Fig. 11) show a fair correlation between observed and theoretical velocity profile and as expected the values of the residual after removing the wind are closer to the Heaps' model. The main deviation from the expected values of velocity are near the bottom for the along-shore component, this is probably due to the tidal rectification residual, which has values of the order of $2 \mathrm{~cm} \mathrm{~s}^{-1}$ as estimated from numerical models (Proctor and Smith, 1991).

\section{Discussion}

The general behavior of the tidal currents are in qualitative agreement with the 2-d barotropic models (Proctor and Smith, 1991), showing close relation in the orientation and phase and in that the ellipses are degenerate within the mixed region. The difference arises within the stratified area, where the tidal surface ellipses have an ellipticity of about -0.3 and rotate in the clockwise sense. This effect cannot be explained by homogeneous theory. 


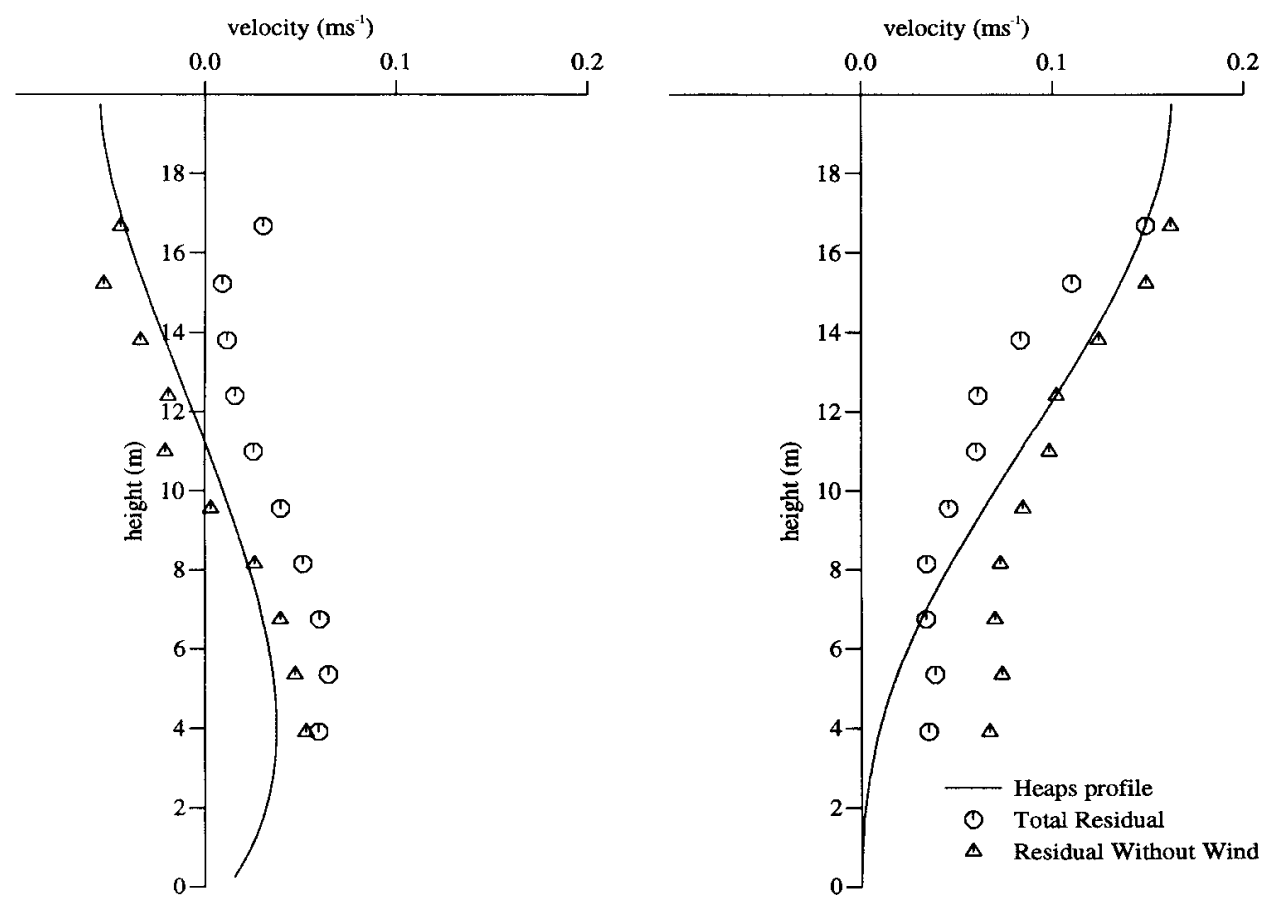

Figure 11. Vertical distribution of velocity as observed by the POL bottom-mounted ADCP at mooring A, between 2 and 17 September 1992; (a) is the cross-shore component; (b) is the along-shore component. Continuous line is the Heaps profile; octagons are the observed total long term residual; triangles are the observed long-term residuals after removing the wind component.

At this latitude, the clockwise and anticlockwise bottom boundary layers are about 30 and $10 \mathrm{~m}$ height respectively, so that the clockwise will cover the entire water column, while the anticlockwise just about half the depth (Souza and Simpson, 1996). In the presence of stratification the pycnocline is located at about $15 \mathrm{~m}$ height, so that the clockwise boundary layer is the only one being decoupled, generating a strong clockwise component at the surface, while decreasing near the bottom (Simpson and Souza, 1996). This has been observed in models that include baroclinic processes, e.g. Souza and James (1996) and Ruddick et al. (1994).

The changes in the tidal ellipse orientation as we approach the coast could be due to the stratification effects as explained in Visser et al. (1994) or to the effect of drying beaches as observed in the Irish Sea (Prandle, 1991). It is interesting to observe that the $\mathrm{S}_{2}$ ellipses appear to be more affected, with the orientation of the ellipses decreasing from about $50^{\circ}$ to about $35^{\circ}$ as we approach the coast. In contrast the $\mathrm{M}_{2}$ ellipses only change about $5^{\circ}$ as we approach the coast. This should be due in part to some barotropic effect as it is in agreement with results of vertically integrated models (e.g. Proctor and Smith, 1991). This stronger changes in orientation for $S_{2}$ are also apparent in the vertical, where the orientation changes 
from about $40^{\circ}$ near the surface to about $55^{\circ}$ near the bottom (Fig. 4), while the $\mathrm{M}_{2}$ ellipses orientation change only about $5^{\circ}$ between near surface and near bottom.

In general we can say that the surface wind-driven currents are rotated, to the right of the wind between $15^{\circ}$ and $45^{\circ}$, and decreasing with depth. The near-bottom currents almost oppose the wind $\left(\Delta \theta \sim 140^{\circ}\right)$. The transfer function of the wind ranges between $2 \%$ at the surface to $0.3 \%$ near the bottom. The above results are in fair agreement with Ekman theory and with previous observations in the North Sea by Prandle (1987) and Prandle and Matthews (1990).

Some differences are apparent between the stratified and mixed regions, in both the horizontal and vertical distribution. The surface maps show that the transfer factor is larger inside the stratified area, while the explained variance is lower. This suggests that the presence of stratification concentrate the wind effect in the surface layer. Similarly the vertical profiles of scaling factor $A$ and rotation angle exhibit different behavior in the stratified and mixed areas. In the stratified area (mooring A) has a surface-bottom difference of $0.8 \%$ for the reduction factor and of $70^{\circ}$ for the rotation angle, in contrast with the mixed case (mooring $\mathrm{B}$ ) where vertical changes in transfer factor and rotation angle are smaller, i.e. $\Delta \mathrm{A} \sim 0.15 \%$ and $\Delta \theta \sim 40^{\circ}$ with a typical scaling factor of about $0.5 \%$.

The effect of stratification is to decouple the bottom layer from the wind effect. In consequence there is a reduction in the transfer function and the explained variance near the pycnocline. The effect of stratification in decoupling the wind-induced currents have been observed directly in the subtidal currents in the 1990 time series (Simpson et al., 1993, Fig. 8). At the start of the time series, the water column is mixed and there is strong correlation between the wind, the near-surface currents and the near-bottom currents. But with the onset of stratification about 6 days later the bottom residual currents are largely decoupled from the surface flow, while the surface currents and wind remain correlated. Proximity to the bottom boundary reduces the transfer factor and the explained variance as we approach the sea bed, in accordance with previous observation and analytical models (Prandle, 1987; Prandle and Matthews, 1990).

In general we can say that the freshwater from the Rhine creates a region of strong cross-shore density gradients, which drive a quasi-geostrophic flow similar to that explained by Heaps (1972), but with additional effects from stratification. The densitydriven flow takes the form of a strong coastal jet extending about $20 \mathrm{~km}$ offshore and with maximum velocities greater than $14 \mathrm{~cm} \mathrm{~s}^{-1}$. There is a related cross-shore convergence zone at $24 \mathrm{~km}$ offshore. Outside the ROFI area the residual flow is weak and does not show any preferential direction. The strong gradients at the outer edge of the coastal current coincide with the ROFI frontal region (see Fig. 7a from Simpson et al., 1993) in which we might expect strong horizontal convergence. Such convergence has been observed in tidal mixing fronts using HF radar (OSCR) and ship-borne ADCP data (Hill et al., 1993); and is also suggested by remote sensing in the Rhine ROFI (Ruddick et al., 1994).

The vertical distribution of velocity inside the ROFI area is explained, to a first order, by Heaps (1972) quasi-geostrophic velocity profile. The strong density gradients generate a 
flow with strong along-shore velocities of the order of $18 \mathrm{~cm} \mathrm{~s}^{-1}$ and moderate cross-shore component of about $5 \mathrm{~cm} \mathrm{~s}^{-1}$. The sulall variations in velocities between the two years of the order of $2 \mathrm{~cm} \mathrm{~s}^{-1}$ are of the order of the instruments resolution. But they might also be due to the difference in stratification between the two years.

We are confident of both the results of the tidal analysis and the residual analysis for the CODAR and bottom mounted ADCP observations as they are in agreement with independent current meter observations (e.g. Simpson $t$ t al., 1993). The criteria of selecting only data which have a time series longer than 8 days and 300 points, ensures that the 6 tidal constituents will be resolve confidently, especially when most of the CODAR stations selected have more than 400 points. The residual analysis is quite robust, as the standard error that we have found is an order of magnitude smaller than the mean velocities. The high percentage of the explained variance, together with the detection of coherent structures such as the coastal jet and convergence region in the right positions, should encourage our confidence in the velocity estimates, even though they are approaching the limits of the accuracy of the instrument $\sim\left(2 \mathrm{~cm} \mathrm{~s}^{-1}\right)$.

A summary of the relative importance of each of the current components can be available in terms of the kinetic energy (K.E.):

$$
\text { K.E. }=1 / 2 \rho U^{2}
$$

assuming that the velocity components behave linearly, the total tidal kinetic energy (K.E.) $)_{\text {total }}$ will be simply the addition of each individual component of the kinetic energy:

$$
(K . E .)_{\text {total }}=(K . E .)_{\text {tid }}+(K . E .)_{\text {wind }}+(K . E .)_{\rho}+(K . E .)_{\text {tidrect }}
$$

$$
(K . E .)_{\text {total }}=1 / 2 \rho U_{\text {tid }}^{2}+1 / 2 \rho U_{\text {wind }}^{2}+1 / 2 \rho U_{\rho}^{2}+1 / 2 \rho U_{\text {tidrect }}^{2}
$$

so that each individual component of the kinetic energy is: $(K . E)_{\mathrm{tid}}=328 \mathrm{~J} \mathrm{~m}^{-3}$, $(K . E .)_{\text {wind }}=21 \mathrm{~J} \mathrm{~m}^{-3},(K . E .)_{\rho}=16 \mathrm{~J} \mathrm{~m}^{-3},(K . E .)_{\text {tidrec }}=0.20 \mathrm{~J} \mathrm{~m}^{-3}$ and $(K . E .)_{\text {total }}=$ $365.20 \mathrm{~J} \mathrm{~m}^{-3}$. This means that the currents are tidally dominated, with important wind and density gradient components, while the tidal rectification is negligible. This analysis of the current system is essentially a linear decomposition which implicitly assumes that the interaction of the different components of velocity field may be neglected. We could argue on three counts that this is a reasonable assumption.

(1) The most energetic current components are the tidal constituents $\mathbf{M}_{2}$ and $\mathbf{S}_{2}$. While these constituents do interact weakly to produce higher harmonics, these resulting terms $\left(\mathrm{MS}_{4}\right.$, etc.) are very small in relation to the semidiurnal constituents (typically less than $10 \%$ of the $\mathrm{M}_{2}$ ).

(2) Similarly it is known that the interaction between storm surge and tides in these areas is generally rather small except in conditions of extreme windstress (Flather, 1987; Prandle and Wolf, 1978). 
(3) Our analysis, on the basis of linear superposition of current components, leads to an explanation of a high proportion of the total variance $\left(R^{2} \geq 90 \%\right)$.

It is also important to note the effect that stratification has in concentrating the frictional effects. In the case of the tidal currents, the bottom ellipses become more clockwise because the frictional effect over the anticlockwise component is concentrated on the bottom layer (Souza and Simpson, 1996). Similarly in the case of the wind-driven circulation, both the intensity and the explained variance increase on the surface layer in the presence of stratification.

Acknowledgments. This work was conducted within PROFILE, an European funded project under the MAST program, contract number MAS2-CT93-0054. A. J. Souza wishes to thank CONACyT, Mexico for the studentship provided. We also want to thank POL for their technical support and for allowing us to use their bottom-mounted ADCPs.

\section{REFERENCES}

Barrick, D. E., M. W. Evans and B. L. Weber. 1977. Ocean surface currents mapped by radar. Science, 198, 138-144.

Flather, R. A. 1987. Estimates of extreme conditions of tide and surge using a numerical model of the northwest European continental shelf. Estua., Coast. Shelf Sci., 24, 69-93.

Godin, G. 1972. The Analysis of Tides, Liverpool University Press, Liverpool, 264 pp.

Heaps, N. S. 1972. Estimation of density currents in Liverpool area of Irish Sea. Geophys. J. R. Ast. Soc., 30, 415-432.

Hill, A. E., I. D. James, P. F. Linden, J. P. Matthews, D. Prandle, J. H. Simpson, E. M. Gmtrowicz, D. A. Smeed, K. M. M. Lwiza, R. Durazo, A. D. Fox and D. G. Bowers. 1993. Dynamics of tidal mixing fronts in the North Sea. Phil. Trans. R. Soc. Lond., A343, 431-446.

Linden, P. F. and J. E. Simpson. 1988. Modulated mixing and frontogenesis in shallow seas and estuaries. Cont. Shelf. Res., 8, 1107-1127.

Prandle, D. 1984. A modelling study of Mixing of 137Cs in the European Continental Shelf. Phil. Trans. R. Soc. Lond., A343, 405-421.

— 1987. The fine-structure of nearshore tidal and residual circulation revealed by H. F. radar surface current measurements. J. Phys. Oceanogr., 17, 231-245.

- 1991. A new view of nearshore dynamics based on observations from HF Radar. Progr. Oceanogr., 27, 403-438.

Prandle, D. and J. Matthews. 1990. The dynamics of nearshore surface currents generated by tides, wind and horizontal density gradients. Cont. Shelf Res., 10, 665-681.

Prandle, D. and J. Wolf. 1978. Surge-tide interaction in the southern North Sea, in Hydrodynamics of Estuaries and Fjords, J. C. J. Nihoul, ed., Elsevier Scientific Publishing Company, Amsterdam, $161-185$.

Proctor, R. and J. A. Smith. 1991. The depth-average residual circulation on the northwest European shelf August 1988-October 1989. Proudman Oceanographic Laboratory Report no. 20.

Pugh, D. T. 1987. Tide Surges and Mean Sea-Level, John Wiley and Sons, Chichester, 472 pp.

Ruddick, K. G., E. Deleersnijder, T. De Mulder and P. J. Luyten. 1994. A model study of the Rhine discharge front and circulation. Tellus, 46, 149-159.

Simpson, J. H., W. G. Bos, F. Schirmer, A. J. Souza, T. P. Rippeth, S. E. Jones and D. Hydes. 1993. Periodic stratification in the Rhine ROFI in the North Sea. Oceanologica Acta, 16, 23-32. 
Simpson, J. H. and A. J. Souza. 1995. Semi-diurnal switching of stratification in the Rhine ROFI, J. Geophys. Res., 100, (C4), 7037-7044.

Souza, A. J. and I. D. James. 1996. A two-dimensional $(x-z)$ model of tidal straining in the Rhine ROFI. Cont. Shelf Res., 16, 949-966.

Souza, A. J. and J. H. Simpson. 1996. The modification of the tidal ellipses by stratification in the Rhine ROFI. Cont. Shelf Res., 16, 997-1007.

Visser, A. W., A. J. Souza, K. Hessner and J. H. Simpson. 1994. The influence of water column stratification on tidal current profiles in a ROFI system. Oceanlogogica Acta, 17, 369-381.

Received: 30 May, 1996; revised: 7 November, 1996. 